Virtual Mentor. August 2004, Volume 6, Number 8.

doi: 10.1001/virtualmentor.2004.6.8.msoc1-0408

Medicine and Society

\title{
Presymptomatic Genetic Testing for Neurodegenerative Diseases
}

\section{Presymptomatic genetic testing for neurodegenerative diseases can help patients make effective treatment decisions, but the medical profession needs to ensure that the increasing use of the tests is done responsibly.}

\author{
Shane K. Green, $\mathrm{PhD}$
}

A few years ago, I was asked by someone very close to me whether I, as her genetics-savvy friend, thought she should undergo genetic testing to determine carrier status for a particular polymorphism that has been linked to Alzheimer's disease (AD), namely the e4 allele of apolipoprotein E (APOE). She had witnessed her father's slow deterioration and eventual death from $\mathrm{AD}$, and feared, as she still does, that the same fate awaited her many years down the road. Having read a news item-or was it a website?_-describing, or rather overstating, the link between APOE e4 and AD, she was considering facing her fear head-on by going to be tested for Alzheimer's.

"You're asking the wrong kind of doctor," I thought. So I advised her to seek the guidance of her physician, but not before directing her to numerous consensus statements issued by neurologists, geneticists, and medical ethicists that universally recommend against presymptomatic APOE genotype testing because of its low predictive value [1]. Though she decided not to pursue testing, her story has left me thinking ever since about the similar choices facing growing numbers of people as our understanding of the genetic underpinnings of disease continues to make great strides forward.

If, for example, you could have a genetic test—-that is, obtain a clinical analysis of your DNA — that would tell you whether or not you were likely to be stricken with a terrible disease later in life, would you want to?

To state the obvious, most people have these tests in hopes of negative results (ie, absence of disease-causing genes). Sadly, but inevitably, such hopes are often dashed by tests that come up positive. But many others-in particular, those in families with a history of disease-choose to be tested so that, in the event of a positive test, they can make lifestyle changes or pursue clinical interventions that may alter the course of the disease(s) to which they are predisposed.

A woman in a family with a history of breast cancer, for example, may wish to be tested for an inherited mutation in the BRCA1 gene, which can lead to the development of breast (and ovarian) tumors. A positive test may prompt her to undergo more frequent mammograms to catch tumor development at an early stage when it may be more responsive to treatment or to undertake more drastic measures to protect against cancer developing at all, namely, prophylactic double mastectomy. While these are not enviable options, at least they are options; that is, in such cases, a positive genetic test is accompanied by a choice of preventive or even curative treatments.

This is not true of genetic testing for Huntington disease (HD) or Alzheimer's disease, both neurodegenerative conditions for which there is no treatment that stops the progression of the disease. Individuals considering being tested for either of these diseases must therefore answer another, in some ways more challenging, question:

If you could have a test that would tell you whether or not you were likely to be stricken with an incurable, fatal 
disease later in life, would you want to?

\section{Genetic Testing for HD and AD: A Primer}

Huntington disease (sometimes referred to as Huntington's chorea) is caused by an autosomal dominant genetic variation with 100 percent penetrance-in other words, everyone who inherits an HD gene will eventually develop the disease. Because people have 2 of every autosomal gene (ie, 2 alleles), only 1 of which is passed on to their offspring, children of parents with 1 or $2 \mathrm{HD}$ genes have a 50 or 100 percent chance, respectively, of developing it themselves.

Approximately 30,000 Americans have HD and another 150,000 are at risk of inheriting it from a parent [2]. Symptoms generally begin in affected individuals' 30s or 40s, and last for a mean duration of 17 progressively more difficult years before the disease proves fatal, barring earlier death from other causes. The test for the HD gene is fast, relatively inexpensive, and highly sensitive, with positive and negative predictive values approaching 99 percent.

Unlike HD, there is no single genetic cause of all cases of Alzheimer's disease, which currently affects 4.5 million Americans. Familial, early-onset (before age 65) AD comprises about 10 percent of all AD cases, 50 percent of which (or 5 percent overall) are caused by a heritable mutation in the gene encoding one of 3 proteins: presenilin-1 (PS1), -2 (PS2), or amyloid precursor protein (APP). Like the HD gene, mutations in these genes are dominant, causing AD to develop in nearly 100 percent of people possessing them. Hence, positive tests for these genes, as for the HD gene, are predictive rather than merely suggestive. Unlike the HD test, however, a negative PS1 (or PS2 or APP) test does not rule out the future development of $\mathrm{AD}$ with a different genetic etiology.

Indeed, the vast majority of $\mathrm{AD}$ cases are late-onset and not linked to the aforementioned genes, but instead are believed to be caused by the interaction of multiple genetic and environmental factors; recent twins studies suggest that genes are, in fact, less important than environmental influences in the development of AD [3]. Though studies have identified a number of putative genetic linkages that warrant further examination [4], only the APOE e4 allele has been validated as an $\mathrm{AD}$ risk factor. Individuals who are heterozygous (ie, have 1 allele) or homozygous (have 2 alleles) for APOE e4 have increased lifetime risks of developing AD of about 3-5 or 8-18 times, respectively; however, not all patients with late-onset AD possess the APOE e4 allele, and not all persons possessing the allele develop AD. Simply put, a genetic test for APOE e4 has little predictive value.

\section{Why choose genetic testing for HD or AD?}

With the exception of the APOE e4 risk factor, a positive DNA test for HD or (early-onset) AD means that, if the person lives to middle or late middle age, the disease will manifest, and will be unstoppable once it does. This unfortunate fact is the primary reason why only about 15-25 percent of people at risk for HD get tested [5]. For example, when asked why she has not been tested, Nancy Wexler, PhD, a prominent HD researcher who led the effort to identify the HD gene and herself a member of a family with a history of HD, blamed the lack of available treatment, wondering, "Why do we want this? What's on the plus side" [6]?

In the absence of a possible clinical response, a test confirming or even suggesting future development of a fatal neurodegenerative condition can have a devastating psychological impact on the patient. Moreover, pursuing such a test may strain relationships with and put undue burdens on other family members (eg, identical twin siblings) for whom the patient's test could reveal unwanted information. For the patient and other potentially affected individuals, a positive test could also have a detrimental effect on employment and insurance status. It should be noted, however, that more than 40 states currently have some form of genetic non-discrimination legislation to prevent such an occurrence [7] and federal legislation is pending [8].

This is not to say, however, that no benefit can come from testing. Even a positive test can be of emotional and psychological benefit to patients for whom knowing what lies ahead is preferable to the anxiety born of uncertainty. Foreknowledge can, for example, profoundly influence patient decision making with respect to finances (eg, providing for inevitable hospice care), family planning (eg, marriage or reproduction), and fostering personal relationships. Having insight into one's likely future health status can be empowering, helping to put control over these decisions squarely in one's hands. 
Weighing the risks and benefits of these genetic tests is a decidedly personal endeavor. Hence, guidelines concerning presymptomatic genetic testing for $\mathrm{HD}$ and $\mathrm{AD}$ generally include the following:

- patients must be fully informed and as free as possible from coercive influences (eg, from family members, health care professionals, or direct-to-consumer pharmaceutical advertising) in consenting to be tested;

- only the individual being tested may provide consent (ie, no proxy consent);

- pre-test counseling should be provided to explain the implications of positive and negative results, and to assess family dynamics, cultural issues, financial support, and the emotional and psychological stability of the patient;

- post-test counseling should be provided to help the patient interpret and cope with test results;

- minors should not be tested;

- strict privacy and confidentiality must be maintained.

\section{Looking Ahead}

Genetic research and clinical medicine will continue to build greater understanding of these diseases and their causes, and, in the not-too-distant future, will undoubtedly develop ways to affect and ameliorate how they manifest in patients. As these are discovered, presymptomatic genetic testing will play an increasingly important role in helping patients decide what prophylactic interventions and treatments they can and should make use of, or even what clinical trials of such measures to enroll in.

It is entirely possible, if not likely, that, as with BRCA1 carriers, those with AD genetic risk factors or HD alleles will be forced to weigh the desirability of interventions that are highly toxic, or disfiguring, or otherwise physically or emotionally burdensome against their risk of disease. They will, therefore, become increasingly dependent on the guidance of clinicians and genetic counselors in making these difficult choices.

Already, there is evidence to suggest that the present capacity for genetic counseling is inadequate and will soon be overwhelmed as more people begin to require those critically important services [9]. Let this be a call to the medical profession, then, to put in motion whatever efforts are necessary to ensure that, as presymptomatic genetic testing is used more frequently, it is used as effectively and responsibly as possible.

\section{References}

1. See, for example: National Institute on Aging/Alzheimer's Association Working Group. Apolipoprotein E genotyping in Alzheimer's disease. Lancet. 1996;347:1091-1095; Post SG, Whitehouse PJ, Binstock RH, et al. The clinical introduction of genetic testing for Alzheimer disease. JAMA. 1997;277:832-836.

2. Society for Neuroscience. Huntington's disease genetics. Accessed July 27, 2004.

3. Picard A. Developing Alzheimer's linked to lifestyle more than genes. Globe and Mail. July 22, 2004. Accessed July 29, 2004.

4. Myers AJ, Goate AM. The genetics of late-onset Alzheimer's disease. Curr Opin Oncol. 2001;14:433-440. PubMed Google Scholar

5. Bird TD. Outrageous fortune: the risk of suicide in genetic testing for Huntington disease. Am J Hum Genet. 1999;64:1289-1292; Fogarty M. Genetic testing for people without symptoms of Alzheimer's. genetichealth.com. February 23, 2001. Accessed July 13, 2004.

View Article PubMed Google Scholar

6. Wexler N. Reading genes for disease, Part 3: Huntington's. National Public Radio. Accessed May 26, 2004.

7. National Human Genome Research Institute. Genetic discrimination in health insurance or employment. Accessed July 27, 2004.

8. US Senate. S.1053: Genetic information nondiscrimination act of 2003. Accessed July 26, 2004.

9. Roberts JS, Barber M, Brown TM, et al. Who seeks genetic susceptibility testing for Alzheimer's disease? Findings from a multisite, randomized clinical trial. Genet Med. 2004;6:197-203. 
$\underline{\text { View Article } \underline{\text { PubMed }} \text { Google Scholar }}$

The viewpoints expressed on this site are those of the authors and do not necessarily reflect the views and policies of the AMA.

(c) 2004 American Medical Association. All Rights Reserved. 